\title{
Food labelling, food retail availability and food pricing - moving from research to action?
}

'Making the healthy choice the easy choice' is a commonly heard phrase and seemingly one of the most evident ways to stimulate healthier food choices. Indeed, when about a third of the total global population is overweight or obese $^{(1)}$, it makes little sense to focus entirely on the individual rather than on strategies that can have a population impact. There is a growing call to implement structural interventions such as fiscal policies and front-ofpack labelling to create a more supportive food environment ${ }^{(2-4)}$. This issue of Public Health Nutrition features some of the latest studies in this area, including new work on food labelling ${ }^{(5,6)}$, policy-induced changes in retail food availability $^{(7)}$ and monetary fruit and vegetable incentives $^{(8)}$.

Structural nutrition interventions generally operate at the point of purchase in the retail setting ${ }^{(9,10)}$. Two of the most important food retail settings are supermarkets and fast-food restaurants. Supermarkets have long been the most important point of purchase for food items in developed countries and their share of retail sales is growing globally, including both developed and developing countries ${ }^{(11)}$. Likewise, fast food provides an increasing share of dietary energy and nutrient intakes, which is concerning since high fast-food intake is associated with increased obesity risk ${ }^{(12,13)}$. Interventions within these retail settings have clear potential to improve the healthfulness of food purchases by making healthy food more available, apparent and affordable.

\section{Food labelling}

Food labelling, along with food pricing, is one of the most promising structural interventions in the retail setting ${ }^{(2)}$. This issue of Public Health Nutrition features two new labelling studies: Cawley et al. investigated the effects of a supermarket nutrition rating system $^{(5)}$ and Liu et al. examined the potential of menu labelling in fast-food restaurants to improve food choices ${ }^{(6)}$.

\section{Fast-food restaurants}

In March 2010, the US President signed the health-care reform legislation into law. As part of this law, restaurants and food outlets with twenty or more locations are now required to list energy (calorie) content information for standard menu items on restaurant menus and menu boards ${ }^{(14)}$. The rationale behind this measure is that calorie labelling will help consumers more accurately estimate energy intakes from fast food ${ }^{(15)}$. However, as Liu et al. point out in this issue ${ }^{(6)}$, many menu items are likely to appear with energy ranges instead of specific energy values. This is because items are customizable; for example, total energy will differ for pizza depending on the selected toppings. These energy ranges might confuse consumers, leading them to misestimate the total energy value of their meal. Also, the authors hypothesize that consumers might confuse the energy range with healthiness, believing that the item with the lowest energy content is the healthiest instead of the item with the least ingredients ${ }^{(6)}$.

In a series of four well-conducted randomized experiments, Liu et al. examine whether energy range information improves energy estimation accuracy (compared with no information) and whether people's energy estimates can be improved by providing explicit information about the contents of items at the end points (identifying the items with the lowest and the highest energy content). In study 1, a total of 306 participants were asked to estimate the energy content of their selected entrée at a fast-food restaurant. They were randomly assigned to see either (i) no energy information or (ii) energy range information. Results revealed that energy estimation significantly improved in the second condition, but consumers continued to misestimate. Studies 2-4 expanded on these results by asking people to select hypothetical fast-food items in an online survey. In addition to the two conditions tested in study 1 , these studies looked at whether pointing people to the energy information and/or adding specific end point content information (ingredients in lowest and highest energy option) would improve accuracy. Results showed that defining the specific end points generally did improve accuracy, but misestimating persisted in some cases. Also, even when participants were specifically asked to pay attention to the range end points, accuracy was not improved - suggesting that inaccuracy is not caused by lack of awareness ${ }^{(6)}$.

These results suggest that energy labelling with ranges on fast-food menus might not have the anticipated impact on improved energy estimation, which is also supported by other study findings ${ }^{(16)}$. If misinterpretation remains, it is unlikely that energy labelling will have a significant impact on the energy content of fast-food purchases or consumption. Indeed, a systematic review (2011) including outcomes from natural and laboratory experiments 
comparing calorie labelling $v$. no labelling on calorie ordering and consumption concluded that its impact was modest at best ${ }^{(17)}$. Likewise, a recent meta-analysis of experimental studies concluded that labelling menus with calorie information alone had no effects on calories selected or consumed $^{(18)}$. On the other hand, a review of quasi-experimental studies showed that the addition of contextual or interpretive information did affect calorie consumption $^{(18)}$, suggesting that the effects of the labels can be enhanced when designed in the right way.

\section{Supermarkets}

This brings us to nutrition labelling in supermarkets, the focus of a study by Cawley et al. in this issue ${ }^{(5)}$. In this setting, labels generally appear either on the front of the pack or on the shelf and provide 'at a glance' information that is easy for consumers to understand and act upon. There is now substantial evidence indicating that interpretative labels (using graphics, symbols or colours) are better understood than quantitative or informative (text) nutrition labels ${ }^{(19)}$. However, evidence of the effects on actual purchases, sales or consumption is more inconclusive $^{(19)}$. This evidence is important as understanding a nutrition label does not necessarily mean people will positively change their purchases. In fact, effects could even be negative because people might link health with a bad taste ${ }^{(20)}$.

Cawley et al.'s study used objective sales data to measure the impact of the introduction of a nutrition labelling system, Guiding Stars, in 168 supermarkets in the USA ${ }^{(5)}$. Beginning in September 2006, Guiding Stars - which assigns scores of zero, one, two or three stars to food items, with three stars indicating the most nutritious - was added on shelf labels. Cawley et al. analysed aggregated weekly sales data from January 2005 to December 2007 and looked at overall weekly food sales, sales of less nutritious foods and sales of nutritious foods before and after the introduction of the labelling. While sales of nutritious foods did not change significantly, weekly sales of less nutritious foods decreased significantly by $8.3 \%$, meaning that the overall nutritional quality of purchases improved. These effects are promising. However, since this study used aggregate sales data and did not have a control group, some important issues remain unclear. First, we do not know how the labels impacted individual consumers or the extent to which population trends or other factors could account for the observed effects. Besides, any effects on purchases outside the participating supermarkets or long-term impacts are uncertain. These are all potential targets of future studies. Still, the fact that this study used objective sales data and was able to monitor the effects of a real-life labelling scheme are significant strengths. There are only a few other studies that have examined impacts of labels on supermarket sales or purchases, and evidence is mixed. Two studies looking at the impact of 'traffic light' nutrition systems did not find significant impacts on unit sales of healthier $v$. unhealthier products $^{(21,22)}$, while two other studies testing the effects of the Guiding Stars programme did find effects on healthier ready-to-eat cereals demand ${ }^{(23)}$ and purchases ${ }^{(24)}$.

\section{Food labelling - conclusion}

Summing up the evidence on labelling, it appears this strategy might have some impact on purchases, but no miracles should be expected. As outlined in earlier work, the best potential for labelling might lie in reformulation, as labels could form an incentive for producers to develop healthier products ${ }^{(25)}$. It can be argued that clear labelling is the least we can do to support consumers in making healthier choices, but other measures are clearly needed to have a real impact.

\section{Food availability}

One way to enhance the effects of nutrition labelling is by increasing the availability and accessibility of healthy food. Principally, if healthy options are not available, of poor quality or expensive, they are not very likely to be purchased, in particular among poorer households who have limited access to resources including cars to travel to food establishments.

As the subject of the study by O'Malley et al. in this issue of Public Health Nutrition ${ }^{(7)}$, food packages for the US Special Supplemental Nutrition Program for Women, Infants, and Children (WIC) ${ }^{*}$ underwent substantial revisions in 2009 to align them with US dietary guidelines. The changes included the addition of low-fat dairy, whole grains and cash vouchers for fruits and vegetables. While the primary goal was to improve dietary quality of the target population, the policy change also required retail stores authorized to accept WIC to meet minimum stocking requirements for the new items. In their study, O'Malley et al. report interesting findings showing that the availability of foods meeting WIC requirements improved significantly pre- to post-policy in small and medium-sized stores. These stores are important points of purchase in many lower-income and racial/ethnic minority neighbourhoods due to the lack of supermarkets. This finding supports other prior published studies showing small improvements in healthier food availability (and pricing) following the WIC food package revision ${ }^{(26-29)}$.

O'Malley et al. examined the impact of the WIC food package revision using a new audit instrument, the WIC Availability Index (WIC-AI), and argue that their instrument is not only useful to monitor WIC adoption but also to measure the healthfulness of retail food environments in general. Advantages of the WIC-AI tool are that it is easy to use and provides a way to summarize complex food

* WIC is the US Special Supplemental Nutrition Program for Women, Infants, and Children providing supplemental food and nutrition education to low-income women, infants and children under the age 5 years. 
store environment data ${ }^{(7)}$. However, as also acknowledged by the authors, there are some shortcomings to consider. For example, as recognized previously by members of the research team and others, there is evidence that not only the availability of healthy items is of importance, but also the availability of unhealthy items ${ }^{(30,31)}$. In fact, when measuring the retail food environment, multiple aspects of the consumer food environment - beyond availability - should be considered, including prices, marketing and food quality (i.e. freshness, expiration dates) ${ }^{(32-34)}$. A large number of food store and even restaurant audit instruments are now available, each with strengths and limitations. As research on the consumer retail food environment continues, investigators need to grapple with achieving the right balance between the creation of innovative tools that improve our ability to capture relevant aspects of the food environment or best suit their study aims $v$. the use of standardized instruments that allow for easier comparisons across places and over time. When making these decisions, researchers may find a recently proposed step-wise framework to monitor local food environments within and across countries useful ${ }^{(35)}$.

\section{Food pricing}

This brings us to the final promising strategy, food pricing. Food pricing interventions can broadly be divided into taxes on unhealthy foods or subsidies on healthy foods. This issue of Public Health Nutrition features a new welldesigned food pricing study on the latter. Andreyeva and Luedicke examined the effects of cash-value vouchers (\$US 10 for women and \$US 6 for children per month) for fruits and vegetables through the WIC programme on fruit and vegetable purchases, using a one-group pre-post design $^{(8)}$. Results showed that the vouchers were effective in increasing monthly fruit and vegetable purchases, with a $17.5 \%$ increase in fresh vegetable and $28.6 \%$ increase in fresh fruit purchases following the introduction of the vouchers. There were some substitution effects (e.g. people now using the vouchers instead of other funds to pay for fruits and vegetables) but these were small and the authors conclude that the efforts to encourage consumption of fruits and vegetables by people receiving federal food assistance are paying off ${ }^{(8)}$.

\section{Effectiveness of food pricing interventions}

The first economic law of demand states that if prices of a certain product increase, the demand will decrease and vice versa ${ }^{(36)}$. Indeed, there is growing evidence supporting the findings by Andreyeva and Luedicke in this issue showing that people are responsive to price changes of food ${ }^{(8,37,38)}$. Also, in other fields it has long been known that price is one of the most effective ways to steer consumer behaviour ${ }^{(39,40)}$ and when thinking about implementing population-wide nutrition interventions, price should definitely be part of the strategy. Nevertheless, it is important to be mindful of some potential side-effects that could influence the ultimate effects of pricing interventions.

For pricing strategies to be effective, we not only want them to impact on purchases of the targeted product (fruit and vegetables, in this issue) but also on the overall healthiness of the purchases. An important limitation of the study by Andreyeva and Luedicke is that it did not examine this overall effect. A concern with healthy food subsidies is that people might purchase the subsidized foods on top of their regular purchases, thereby ending up with a higher total energy value. Or, even worse, people might use the money they saved through the subsidy to buy extra unhealthier items ${ }^{(41,42)}$. Other mechanisms to consider include 'product substitution', 'forward buying', 'purchase acceleration', 'brand switching', 'product testing' and 'repeat purchasing', which all are expected to have different effects on consumption patterns and might not necessarily improve the healthiness of the diet ${ }^{(40)}$. Also, there is the issue of cross-price elasticity which has important consequences for the effectiveness of both subsidies and taxes.

Cross-price elasticity is a term from micro-economics relating to the change in demand of one product (full-fat milk) in response to the change in price of another product (low-fat milk), either through complementing or substitution. When products are complements, they are often purchased together (for example, milk and breakfast cereal) and if the price of one product changes, the demand for both changes. If products are substitutes, it means that people swap one product (regular soft drink) for another (diet soft drink) due to a price change (soft drink tax). These price-elasticity effects can have important impacts on the overall effects of pricing interventions. For example, Mytton and colleagues found that fruit purchases tended to fall as a result of taxation on milk and cream $^{(43)}$ and Nederkoorn and colleagues found that people tended to replace more expensive energy-dense products with cheaper alternatives as a result of a tax on energy-dense foods ${ }^{(44)}$.

There is a clear lack of high-quality studies that have looked into price elasticity effects of food price interventions in detail. Most evidence comes from natural experiments/observational studies and modelling studies which generally do not provide detailed insight into cross-price elasticity effects ${ }^{(45)}$. Apart from a field experiment aiming to simulate a tax by manipulating discount levels on unhealthier items and some experiments in simulated supermarket environments ${ }^{(46,47)}$, no randomized controlled supermarket trials testing the effects of food taxes exist in the literature. The main reason for the dearth of high-quality trials is that they are complex and costly to conduct. Opposition from the food industry against several proposed intervention strategies is another important reason for the lack of experimental studies ${ }^{(48)}$. There are a few examples of high-quality supermarket randomized 
controlled trials on healthy food subsidies ${ }^{(49-51)}$. While no randomized controlled trial, the paper by Andreyeva and Luedicke in this issue of Public Health Nutrition is an important addition to this evidence base and key strengths include that it was conducted in a real-life supermarket setting and used objective loyalty card purchasing data of a large sample of 2137 households. With other studies showing that the cash-value vouchers were also associated with small improvements in fruit and vegetable availability $^{(27)}$ and pricing ${ }^{(28,29)}$ and improvements in dietary intakes ${ }^{(52)}$, vouchers for fruits and vegetables and possibly other healthier foods seem a promising strategy worth further investigation ${ }^{(50)}$, particularly since they can be directly targeted to the groups most in need of this intervention.

Finally, the major challenge in future food pricing research is to unfold the effects on health outcomes. This includes not only estimating more precise price elasticities, but also the long-term effects of price changes. People may eventually become unaware of new prices, especially when prices of a whole product range are changed at a certain point in time ${ }^{(53)}$. An important aspect to also consider is tax salience, referring to how the tax/subsidy is communicated. Here, it may be more important to tell people that products are taxed than to actually tax them ${ }^{(54)}$. Also, we should not forget the importance of industry response to taxes and subsidies. Companies can make decisions about absorbing (parts of) the tax and the cost change might only be partially passed on to the consumer. Furthermore, the abolishment of the Danish fat tax (mainly for economic reasons) within one year of its introduction shows that feasibility aspects are crucial to consider ${ }^{(55)}$

In conclusion, there is still much to learn about the effects of food taxes and subsidies, however time is ripe for action too. It is encouraging that different countries, including Hungary, France and Mexico, have introduced fiscal food policies ${ }^{(56)}$ and it would be very interesting to learn the effects of these policies to inform further policy making.

\section{Conclusion}

The papers discussed in this editorial show potential for several structural nutrition interventions including food labelling, retail food availability and pricing interventions. While some important evidence is still missing, most importantly regarding the long-term effects of these interventions and the effects on dietary and health outcomes, the rising prevalence of obesity and noncommunicable diseases also calls for more immediate action and the time seems right to start implementing a range of promising measures.

It is evident that our food environment is highly commercialized and it has been argued that unhealthy diets are simply the consequence of peoples' incapability of choosing right from plenty ${ }^{(57)}$ or that obesity is 'a robust sign of commercial success' ${ }^{(58)}$. If we are serious about population health, we should do something to change this environment, which might include doing something about vested commercial and political interests. There is clear evidence showing that promotional campaigns or nutrition education are not enough to achieve healthier population $\operatorname{diets}^{(59)}$. Indeed, as outlined in a recent viewpoint in $J A M A$, we need governments and health bodies to take action and lead by example ${ }^{(60)}$. Incentives such as the Danish fat tax should be given the opportunity to prove effects before being overturned by giving priority to other (economic or political) interests. Also, we should be mindful that the introduction of less hefty interventions, such as calorie labelling, are not used as 'window-dressing' and confine the introduction of any further measures. Calorie labelling is arguably the least we can do and should be seen as a first step to create healthier food environments. A range of measures are clearly needed where it is crucial that health, as opposed to economic interests, achieves a central role in food policy decisions.

Wilma E Waterlander and Shannon N Zenk Associate Editors

Email: w.waterlander@auckland.ac.nz; szenk@uic.edu

\section{References}

1. Ng M, Fleming T, Robinson M et al. (2014) Global, regional, and national prevalence of overweight and obesity in children and adults during 1980-2013: a systematic analysis for the Global Burden of Disease Study 2013. Lancet $\mathbf{3 8 4}$, 766-781.

2. Gortmaker SL, Swinburn BA, Levy D et al. (2011) Changing the future of obesity: science, policy, and action. Lancet 378, 838-847.

3. Swinburn BA, Sacks G, Hall KD et al. (2011) The global obesity pandemic: shaped by global drivers and local environments. Lancet 378, 804-814.

4. Roberto CA, Pomeranz JL \& Fisher JO (2014) The need for public policies to promote healthier food consumption: a comment on Wansink and Chandon (2014). J Consum Psychol 24, 438-445.

5. Cawley J, Sweeney MJ, Just DR et al. (2015) The impact of a supermarket nutrition rating system on purchases of nutritious and less nutritious foods. Public Health Nutr $\mathbf{1 8}$, $8-14$.

6. Liu JL, Bettman JR, Uhalde AR et al. (2015) How many calories are in my burrito? Improving consumers' understanding of energy (calorie) range information. Public Health Nutr 18, 15-24.

7. O'Malley K, Luckett BG, Futrell Dunaway L et al. (2015) Use of a new availability index to evaluate the effect of policy changes to the Special Supplemental Nutrition Program for Women, Infants, and Children (WIC) on the food environment in New Orleans. Public Health Nutr 18, $25-32$.

8. Andreyeva $\mathrm{T} \&$ Luedicke $\mathrm{J}$ (2015) Incentivizing fruit and vegetable purchases among participants in the Special Supplemental Nutrition Program for Women, Infants and Children. Public Health Nutr 18, 33-41. 
9. Feng J, Glass TA, Curriero FC et al. (2010) The built environment and obesity: a systematic review of the epidemiologic evidence. Health Place 16, 175-190.

10. Holsten JE (2009) Obesity and the community food environment: a systematic review. Public Health Nutr 12, 397-405.

11. Regmi A \& Gehlhar M (2005) Processed food trade pressured by evolving global supply chains. Amber Waves 3, issue 1. http://www.ers.usda.gov/amber-waves/2005-february/ processed-food-trade-pressured-by-evolving-global-supplychains.aspx\#.VEiqrSx0zhg (accessed 23 October 2014).

12. Fraser LK, Edwards KL, Cade JE et al. (2011) Fast food, other food choices and body mass index in teenagers in the United Kingdom (ALSPAC): a structural equation modelling approach. Int J Obes (Lond) 35, 1325-1330.

13. De Vogli R, Kouvonen A \& Gimeno D (2014) The influence of market deregulation on fast food consumption and body mass index: a cross-national time series analysis. Bull World Health Organ 92, 99-107.

14. US Food and Drug Administration (2013) Menu \& vending machines labeling requirements. http://www.fda. gov/Food/IngredientsPackagingLabeling/LabelingNutrition/ ucm217762.htm (accessed 23 October 2014).

15. Block JP, Condon SK, Kleinman K et al. (2013) Consumers' estimation of calorie content at fast food restaurants: cross sectional observational study. BMJ 346, f2907.

16. Elbel B (2011) Consumer estimation of recommended and actual calories at fast food restaurants. Obesity (Silver Spring) 19, 1971-1978.

17. Swartz JJ, Braxton D \& Viera AJ (2011) Calorie menu labeling on quick-service restaurant menus: an updated systematic review of the literature. Int J Behav Nutr Phys Act 8, 135.

18. Sinclair SE, Cooper M \& Mansfield ED (2014) The influence of menu labeling on calories selected or consumed: a systematic review and meta-analysis. J Acad Nutr Diet 114, 1375-1388. e15.

19. Hersey JC, Wohlgenant KC, Arsenault JE et al. (2013) Effects of front-of-package and shelf nutrition labeling systems on consumers. Nutr Rev 71, 1-14.

20. Horgen KB \& Brownell KD (2002) Comparison of price change and health message interventions in promoting healthy food choices. Health Psychol 21, 505-512.

21. Sacks G, Rayner M \& Swinburn B (2009) Impact of front-ofpack 'traffic-light' nutrition labelling on consumer food purchases in the UK. Health Promot Int 24, 344-352.

22. Sacks G, Tikellis K, Millar L et al. (2011) Impact of 'trafficlight' nutrition information on online food purchases in Australia. Aust N Z J Public Health 35, 122-126.

23. Rahkovsky I, Lin BH, Lin CTJ et al. (2013) Effects of the Guiding Stars Program on purchases of ready-to-eat cereals with different nutritional attributes. Food Policy 43, 100-107.

24. Sutherland LA, Kaley LA \& Fischer L (2010) Guiding Stars: the effect of a nutrition navigation program on consumer purchases at the supermarket. Am J Clin Nutr 91, issue 4, 1090s-1094s.

25. Vyth EL, Steenhuis IHM, Roodenburg AJC et al. (2010) Front-of-pack nutrition label stimulates healthier product development: a quantitative analysis. Int J Behav Nutr Phys Act 7, 65 .

26. Andreyeva T, Luedicke J, Middleton AE et al. (2012) Positive influence of the revised Special Supplemental Nutrition Program for Women, Infants, and Children food packages on access to healthy foods. J Acad Nutr Diet 112, 850-858.

27. Havens EK, Martin KS, Yan J et al. (2012) Federal nutrition program changes and healthy food availability. Am J Prev Med 43, 419-422.

28. Zenk SN, Odoms-Young A, Powell LM et al. (2012) Fruit and vegetable availability and selection: federal food package revisions, 2009. Am J Prev Med 43, 423-428.
29. Zenk SN, Powell LM, Odoms-Young AM et al. (2014) Impact of the revised Special Supplemental Nutrition Program for Women, Infants, and Children (WIC) food package policy on fruit and vegetable prices. J Acad Nutr Diet 114, 288-296.

30. Rose D, Hutchinson PL, Bodor JN et al. (2009) Neighborhood food environments and body mass index: the importance of in-store contents. Am J Prev Med 37, 214-219.

31. Zenk SN, Powell LM, Rimkus L et al. (2014) Relative and absolute availability of healthier food and beverage alternatives across communities in the United States. Am J Public Health 104, 2170-2178.

32. Glanz K, Sallis JF, Saelens BE et al. (2005) Healthy nutrition environments: concepts and measures. Am J Health Promot 19, 330-333, ii.

33. Swinburn B, Sacks G, Vandevijvere S et al. (2013) INFOR MAS (International Network for Food and Obesity/noncommunicable diseases Research, Monitoring and Action Support): overview and key principles. Obes Rev 14, Suppl. $1,1-12$.

34. Zenk SN, Schulz AJ, Izumi B et al. (2012) Development, evolution, and implementation of the food environment audit for diverse neighborhoods. In Methods for Conducting Community-based Participatory Research for Health, pp. 277-302 [B Israel, E Eng, A Schulz et al., editors]. San Francisco, CA: Jossey Bass.

35. Ni Mhurchu C, Vandevijvere S, Waterlander W et al. (2013) Monitoring the availability of healthy and unhealthy foods and non-alcoholic beverages in community and consumer retail food environments globally. Obes Rev 14, Suppl. 1, 108-119.

36. McCarthy M (2004) The economics of obesity. Lancet $\mathbf{3 6 4}$, 2169-2170.

37. An R (2013) Effectiveness of subsidies in promoting healthy food purchases and consumption: a review of field experiments. Public Health Nutr 16, 1215-1228.

38. Andreyeva T, Long MW \& Brownell KD (2010) The impact of food prices on consumption: a systematic review of research on the price elasticity of demand for food. Am J Public Health 100, 216-222.

39. Han S, Gupta S \& Lechmann DR (2001) Consumer price sensitivity and price thresholds. J Retailing 77, 435-456.

40. Hawkes C (2009) Sales promotions and food consumption. Nutr Rev 67, 333-342.

41. Waterlander WE, Steenhuis IH, de Boer MR et al. (2012) Introducing taxes, subsidies or both: the effects of various food pricing strategies in a web-based supermarket randomized trial. Prev Med 54, 323-330.

42. Epstein LH, Dearing KK, Roba LG et al. (2010) The influence of taxes and subsidies on energy purchased in an experimental purchasing study. Psychol Sci 21, 406-414.

43. Mytton O, Gray A, Rayner M et al. (2007) Could targeted food taxes improve health? J Epidemiol Community Health 61, 689-694.

44. Nederkoorn C, Havermans RC, Giesen JC et al. (2011) High tax on high energy dense foods and its effects on the purchase of calories in a supermarket: an experiment. Appetite 56, 760-765.

45. Eyles H, Ni Mhurchu C, Nghiem N et al. (2012) Food pricing strategies, population diets, and non-communicable disease: a systematic review of simulation studies. PLOS Med 9, e1001353.

46. Epstein LH, Jankowiak N, Nederkoorn C et al. (2012) Experimental research on the relation between food price changes and food-purchasing patterns: a targeted review. Am J Clin Nutr 95, 789-809.

47. Waterlander WE, Ni Mhurchu C \& Steenhuis IH (2014) Effects of a price increase on purchases of sugar sweetened beverages. Results from a randomized controlled trial. Appetite 78, 32-39. 
48. Stanford DD (2012) Anti-obesity soda tax fails as lobbyists spend millions: retail. Bloomberg Business Week, 13 March 2012. http://www.bloomberg.com/news/2012-03-13/antiobesity-soda-tax-fails-as-lobbyists-spend-millions-retail.html (accessed 23 October 2014).

49. Ni Mhurchu C, Blakely T, Jiang Y et al. (2010) Effects of price discounts and tailored nutrition education on supermarket purchases: a randomized controlled trial. Am J Clin Nutr 91, 736-747.

50. Waterlander WE, de Boer MR, Schuit AJ et al. (2013) Price discounts significantly enhance fruit and vegetable purchases when combined with nutrition education: a randomized controlled supermarket trial. Am J Clin Nutr 97, 886-895.

51. Escaron AL, Meinen AM, Nitzke SA et al. (2013) Supermarket and grocery store-based interventions to promote healthful food choices and eating practices: a systematic review. Prev Chronic Dis 10, E50.

52. Odoms-Young AM, Kong A, Schiffer LA et al. (2014) Evaluating the initial impact of the revised Special Supplemental Nutrition Program for Women, Infants, and Children (WIC) food packages on dietary intake and home food availability in African- American and Hispanic families. Public Health Nutr 17, 83-93.
53. Nijs RN, Dekimpe MG, Steenkamp J-BEM et al. (2001) The category-demand effects of price promotions. Mark Sci $\mathbf{2 0}$, $1-22$.

54. Lacaniloa RD, Cash SB \& Adamowisz WL (2011) Heterogeneous consumer responses to snack food taxes and warning labels. J Consum Affairs 45, 108-122.

55. Stafford N (2012) Denmark cancels 'fat tax' and shelves 'sugar tax' because of threat of job losses. BMJ $\mathbf{3 4 5}$, e7889.

56. Mytton OT, Clarke D \& Rayner M (2012) Taxing unhealthy food and drinks to improve health. BMJ 344, e2931.

57. Tillotson JE (2004) America's obesity: conflicting public policies, industrial economic development, and unintended human consequences. Annu Rev Nutr 24, 617-643.

58. Swinburn BA (2008) Obesity prevention: the role of policies, laws and regulations. Aust $N Z$ Health Policy 5, 12.

59. Rekhy R \& McConchie R (2014) Promoting consumption of fruit and vegetables for better health. Have campaigns delivered on the goals? Appetite 79, 113-123.

60. Gostin LO, Reeve BH \& Ashe M (2014) The historic role of boards of health in local innovation: New York City's soda portion case. JAMA 312, 1511-1512. 